\title{
The surprising influence of family history to type 2 diabetes on anaerobic performance of young male élite athletes
}

\author{
Antonino Bianco ${ }^{1 *}$, Francesco Pomara ${ }^{2}$, Antonino Patti ${ }^{1}$, Ewan Thomas ${ }^{1}$, Marco Petrucci ${ }^{1}$, Marianna Bellafiore ${ }^{1}$, \\ Giuseppe Battaglia ${ }^{1}$, Antonio Paoli ${ }^{3}$ and Antonio Palma ${ }^{1}$
}

\begin{abstract}
Aims/Hypothesis: It is known that family history to type 2 diabetes induces anthropometric changes in various populations. Regular physical activity can induce adaptations in these subjects regularizing body composition and anthropometric parameters. The aim of this study is therefore to understand if family history to type 2 diabetes affects anaerobic performance in young male élite athletes.

Methods: Forty six young male élite athletes were tested. Thirty three without family history to type 2 diabetes $(\mathrm{FH}-)$ and thirteen with family history to type 2 diabetes (FH+). Anthropometric parameters, body composition, physiological parameters and athletic performance were assessed.

Results: Weight ( $p$ 0,0050), BMI ( 0 0,0019), waist circumference ( $p 0,0090)$, hips circumference $(p 0,0490)$ and WHR ( $p$ 0,0339) were different between the two groups, showing greater values for the $\mathrm{FH}+$ subjects. Body composition showed lower FM and higher FFM percentages for the FH + group compared to the FH-. Anaerobic performance tests showed differences between the groups highlighting that the $\mathrm{FH}+$ group had higher anaerobic performance values (Wingate test for FH +512,77 $\pm 107,93$ W vs Wingate test for FH- 447,94 $\pm 56,95$ W).

Conclusions/Interpretation: The élite athletes with $\mathrm{FH}+$ showed better anaerobic performances and a higher body mass. At this stage we cannot generalise, but in a sample of athletes we tested, all who were with $\mathrm{FH}+$ showed both interesting and unexpected results; if confirmed, this evidence may represent a remarkable knowledge for fitness coaches and professionals who are daily dealing with track and field athletes and their performances.
\end{abstract}

Keywords: Type 2 diabetes; Anaerobic performance; Élite athletes; Family history; Wingate test; Track and field; Performance

\section{Introduction}

In occidental industrialized countries, type 2 diabetes (T2D) is a widespread disease, showing a constant increase of its incidence also in a young population (Bianco et al. 2013). Moreover even genetic and environmental risk factors seem to influence T2D development: family history, age, obesity and physical inactivity are the major (Mahajan et al. 2013). The hereditary mechanisms of T2D have been also demonstrated in women with positive family history

\footnotetext{
* Correspondence: antonino.bianco@unipa.it

${ }^{1}$ Sport and Exercise Sciences Research Unit, University of Palermo, Via Eleonora Duse 2, 90146 Palermo, Italy

Full list of author information is available at the end of the article
}

(FH) to the illness confirming the inter-generative transmission of this disease (Erasmus et al. 2001; Crispim et al. 2006; Rodekamp et al. 2005; Plagemann et al. 2002; Bjornholt et al. 2000, 2001; Grill et al. 1999; Rosenbaum et al. 2013). Several Authors have also showed that FH to diabetes has an influence on metabolic and anthropometric characteristics (Bianco et al. 2011, 2014). BMI, weight and hip-waist ratio, have been showed to be greater in subjects with FH of T2D compared to those who were not (Pomara et al. 2006). Although, physical activity has been shown to be preventive on the onset of T2D and can be a useful strategy in reducing firstly abdominal obesity and secondly BMI (Kim and Lee 2009; Golubic et al. 2014). There are 
also strong evidence shown in scientific literature underlining that physical activity has a role on normalizing glucose metabolism and body composition. Has shown by Bianco et al. regular physical activity in subjects with family history to this illness can normalize the above mentioned parameters and make them comparable to those of subjects with no FH (Bianco et al. 2011). Moreover increases in aerobic activities improve cardiorespiratory fitness and cardiovascular risk factors and are useful in stabilizing plasma glucose, body composition and insulin resistance (Geidl and Pfeifer 2011; O'Hagan et al. 2013). Other important considerations must be made for anaerobic activities that are also known to be able in improving insulin sensitivity and glucose tolerance (Kourtoglou 2011; Mann et al. 2013) and as a consequence of the practiced activity, increase muscle mass, strength and reduce total fat mass (Kwon et al. 2010). Though, little is still known about the relationship between family history to T2D and physical performance, therefore the objective of this study is to understand how anaerobic performance is affected by family history to T2D in young male élite athletes.

\section{Materials and methods Subjects}

Forty six young male élite athletes practicing track and field were tested. Thirty three (age 23,15 $\pm 5,14$ years, height $171,30 \pm 7,54 \mathrm{~cm}$, weight $64,71 \pm 9,01 \mathrm{~kg}, 7$ endurance athletes and 26 power athletes) did not present $\mathrm{FH}$ to T2D while thirteen (age 25,31 $\pm 4,21$ years, height $174,65 \pm 8,94 \mathrm{~cm}$, weight $76,42 \pm 17,92 \mathrm{~kg}, 3$ endurance athletes and 10 power athletes) did. The subjects were recruited according to our inclusion criteria. They had to be 1) involved in track and field activities from at least 5 years, 2) be involved in competitions and 3) were not using any medication or not suffering from any apparent illness. Anthropometric parameters, body composition, physiological parameters and athletic performance were assessed. Each subject completed a questionnaire in order to determine physical, medical and nutritional history. A standard questionnaire was subsequently administered to assess FH to T2D: subjects with at least a sibling or parent with the illness were coded as "high-degree" (FH+) while subjects without family members with the illness were coded as "with no-familiarity" (FH-); The athletes were enrolled in the study according to the inclusion criteria approved by the ethics committee of the University of Palermo. The principles of the Italian data protection act (196/2003) were observed. All participants provided informed consent. The study was performed in compliance with the Helsinki Declaration.

\section{Anthropometry and body composition}

Weight was measured to the nearest $0.1 \mathrm{~kg}$ with a calibrated physician's scale (Seca 709, Hamburg, Germany), and height to nearest $1 \mathrm{~mm}$ with a wall-mounted stadiometer (Seca 220, Hamburg, Germany). Waist circumference and hip circumference were measured to the nearest $1 \mathrm{~mm}$, and subsequently the waist-hip ratio (WHR) was calculated. All measurements were performed by the same investigator. Body mass index (BMI) was also calculated. Body composition as free-fat mass (FFM) and fat mass (FM) were assessed by whole body impedance analysis at $50 \mathrm{kHz}$ using a bio-electrical analyser (BIA, model 109, RJL Systems, Detroit - MI) following manufacturer's recommended protocol. Patients were previously instructed to avoid alcohol intake and exhausting physical activity on the day before the exam and to limit food or fluid intake to $4 \mathrm{~h}$ before the test.

\section{Physiological parameters}

Basal metabolic rate (BMR), $\mathrm{VO}_{2}$ Max, Heart rate (HR) and blood lactate (BL) were assessed. BMR was measured inside a quiet and comfortable darkened room, with a temperature between 22 and $24^{\circ} \mathrm{C}$, in the morning between 8:30 and 10:30, following an overnight fast and a standardised meal consumed before 9:00 pm of the preceding evening. Subjects were euhydrated and had refrained from exercise for at least $36 \mathrm{~h}$. After a habituation period of 10-15 min, BMR was recorded continuously for at least $30 \mathrm{~min}$ by an open-circuit indirect calorimetry in dilution testing mode (Vmax $29 \mathrm{~N}$ Sensormedics Italia Srl, Milano, Italy), using a perspex canopy. Oxygen was measured using a gas analyser, on the basis of the high paramagnetic susceptibility of oxygen; carbon dioxide levels were determined by an analyzer using the rapid-Response Non-Dispersive Infrared (NDIR) measurement technique. Values were averaged over 1-min intervals and recorded in a raw data file. BMR was expressed in $\mathrm{Kcal}$ per $24 \mathrm{hr}$ ( $\mathrm{Kcal} /$ day), $\mathrm{VO}_{2}$ Max was measured telemetrically using an oxygen analyser (K4B2, Cosmed, Italy). The laboratory experiments were conducted under standard conditions of temperature and humidity. HR was monitored using a Polar ${ }^{\circledR}$ Heart rate monitor (wireless double electrode). VO2 Max and HR were measured during an incremental treadmill test until muscle exhaustion. VO2 Max was expressed in absolute values $(\mathrm{L} / \mathrm{min})$ and $\mathrm{HR}$ in beats per minute $(\mathrm{bpm})$. BL was analyzed using an Accutrend Lactate photometric test in vitro, Roche Diagnostic GmbH, Germany. For each subject $\mathrm{BL}$ was recorded at regular intervals: basal values before the tests and 2, 4, 6 and 8 minutes after anaerobic testing, during recovery.

\section{Athletic performance}

Each subject had to perform a squat jump and a Wingate test. The squat test was performed squatting down until the knees were bent at 90 degrees, while swinging the arms back behind the body. Without pausing, the arms were 
swung forwards and the athletes had to jump as high as possible, landing back on the mat on both feet at the same time. The best of three attempts was took in consideration. Height and flying time were recorded trough a BOSCO platform (Byomedic, S.C.P., Barcelona, Spain).

Subsequently, after a 5 minute rest, each subject had to perform a cycle Wingate test trough a cycle sonar Ergomedic 894E Peak Bike (Germany). After a low intensity warm up, athletes started to cycle at maximal speed without any resistance. After three seconds a researcher inserted a standard resistance ( $75 \mathrm{~g} / \mathrm{kg}$ of weight); Athletes had to cycle for 30 seconds at maximal velocity; a software recorded and stored resistance and cycle velocity variations during the test. Peek power output was then used for statistical analysis.

\section{Statistical analysis}

All data were recorded on an Excel file for Windows. Differences between the two groups ( $\mathrm{FH}+$ and $\mathrm{FH}-$ ) were assessed using an unpaired two tailed $t$ test. Data processing was performed using Statistica 8.0 for Windows (Statsoft Inc., Tulsa, OK, USA). Significance level was set at $p<0.05$ for all analyses.

\section{Results}

Significant differences were shown for anthropometric parameters between groups. Weight $(p 0,0050)$, BMI $(p$ 0,0019), waist circumference ( $\mathrm{p} 0,0090$ ), hip circumference ( $\mathrm{p} 0,049)$, WHR $(p 0,0339)$, showing greater values for the $\mathrm{FH}+$ subjects (Table 1 ).

No differences were found regarding any of the physiological parameters, although the $\mathrm{FH}+$ group showed higher BMR and lower percentage values of FM $(18,74 \pm 5,69 \%)$ compared to the FH- $(19,90 \pm 5,77 \%)$ even if not statistically different $(p 0,189)$ and higher FFM $(81,26 \pm 5,69)$ compared to the FH- $(80,10 \pm 5,77)(\mathrm{p} 0,0040)$ (Table 2).

Regarding anaerobic performance both tests showed significant differences. The squat jump of the $\mathrm{FH}+$ group was greater than the $\mathrm{FH}$ - both in height $(37,12 \pm 7 \mathrm{~cm}$ vs. $33,23 \pm 6,95 \mathrm{~cm}$, respectively) ( $p 0,0379)$ and flying time $(548,15 \pm 52,89 \mathrm{~ms}$ vs. $509,82 \pm 55,01 \mathrm{~ms}$, respectively) $(p 0,0370)$ as shown in Figures 1,2 as also the Wingate test $(512,77 \pm 107,93$ W vs. $447,94 \pm 56,95 \mathrm{~W}$, for $\mathrm{FH}+$ and $\mathrm{FH}-$, respectively) $(p 0,0116)$ as shown in Figure 3.

Table 1 Participants' characteristics

\begin{tabular}{lccc}
\hline Characteristic & FH- $(\boldsymbol{n}=\mathbf{3 3})$ & FH $+(\boldsymbol{n}=\mathbf{1 3})$ & $\boldsymbol{p}$ value \\
\hline Age (years) & $23,15 \pm 5,14$ & $25,31 \pm 4,21$ & $\mathrm{~ns}$ \\
Height $(\mathrm{cm})$ & $171,30 \pm 7,54$ & $174,65 \pm 8,94$ & ns \\
Weight $(\mathrm{kg})$ & $64,71 \pm 9,01$ & $76,42 \pm 17,92$ & 0.0050 \\
BMI $\left(\mathrm{kg} / \mathrm{m}^{2}\right)$ & $21,96 \pm 1,88$ & $24,76 \pm 3,90$ & 0,0019 \\
WHR & $0,94 \pm 0,05$ & $0,97 \pm 0,03$ & 0,0262 \\
\hline
\end{tabular}

Table 2 Physiological parameters

\begin{tabular}{lccc}
\hline & FH- $(\boldsymbol{n}=\mathbf{3 3})$ & $\mathbf{F H}+(\boldsymbol{n}=\mathbf{1 3})$ & $\boldsymbol{p}$ value \\
\hline $\mathrm{BMR}($ calories/day) & $1450 \pm 23,71$ & $1619 \pm 73,06$ & 0,0501 \\
$\mathrm{VO}_{2 \mathrm{max}}\left(\mathrm{ml} / \mathrm{kg} / \mathrm{min}^{-1}\right)$ & $4112 \pm 175,1$ & $4413 \pm 215,4$ & 0,3259 \\
$\mathrm{MHR}(\mathrm{beats} / \mathrm{min})$ & $188,5 \pm 1,634$ & $189,0 \pm 3,017$ & 0,8838 \\
$\mathrm{BL}(\mathrm{mmol} / \mathrm{l}) 2$ min rest & $10,12 \pm 0,8934$ & $11,24 \pm 1,789$ & 0,5377 \\
$\mathrm{BL}(\mathrm{mmol} / \mathrm{l}) 4$ min rest & $9,838 \pm 0,6484$ & $10,04 \pm 0,124$ & 0,9644 \\
$\mathrm{BL}(\mathrm{mmol} / \mathrm{l}) 6$ min rest & $8,746 \pm 0,5906$ & $9,903 \pm 0,8621$ & 0,4168 \\
$\mathrm{BL}(\mathrm{mmol} / \mathrm{l}) 8$ min rest & $7,371 \pm 0,6143$ & $8,249 \pm 0,8072$ & 0,4378 \\
\hline
\end{tabular}

The results highlight that the $\mathrm{FH}+$ group show to some extent higher anaerobic performance values (Table 3 ).

\section{Discussion}

The study results are in line with scientific literature, showing higher values in subjects with FH to T2D (Bianco et al. 2011, 2014). In our previous study we analyzed whether physical activity could influence basal metabolic rate in sedentary and active women with FH to T2D and the results show that active women, had similar basal metabolic rates compared to those with no FH to T2D, despite this familiarity to the illness; on that case physical activity played a key role on a FFM and BMR maintenance (Bianco et al. 2011). In this study élite athletes were compared; this particular sample (élite athletes) allows us to state that the differences found between the groups could not be determined by differences in their physical level. The only independent variable of our sample is in fact FH to T2D. Although, it has been noticed that the majorities of studies regarding FH to T2D mainly investigate on the effects of aerobic exercise on health (Ekelund et al. 2007; Nyholm et al. 2004), regarding subjects with $\mathrm{FH}$ to T2D little was known about the relationship of this hereditary profile with physical performance. Moreover, the choice of the Wingate test for the assessment of peak power output was not accidental; though Hawley and Gibala don't recommend the use of "all out" tests in a clinical population (Hawley and Gibala 2012), the strong physical conditioning to which these athletes undergo has allowed us to administer this test. The results show higher anaerobic peak power outputs in the $\mathrm{FH}+$ group compared to the FH-.

Scientific literature has recently started studying anaerobic exercise interventions on subjects with T2D and the main outcomes show that these type of activities help reducing fat mass, elicit strength and prevent lean mass loss (Kwon et al. 2010). Anaerobic activities also help enhancing the uptake of glucose in the muscle (Christ-Roberts et al. 2003; Mann et al. 2013; Gordon et al. 2013) and have a role in treating bone dysfunctions in this particular clinical population (Wood and O'Neill 2012). Recently, Nitert et al. published an interesting study on impact 


\section{Squat Jump - Height}

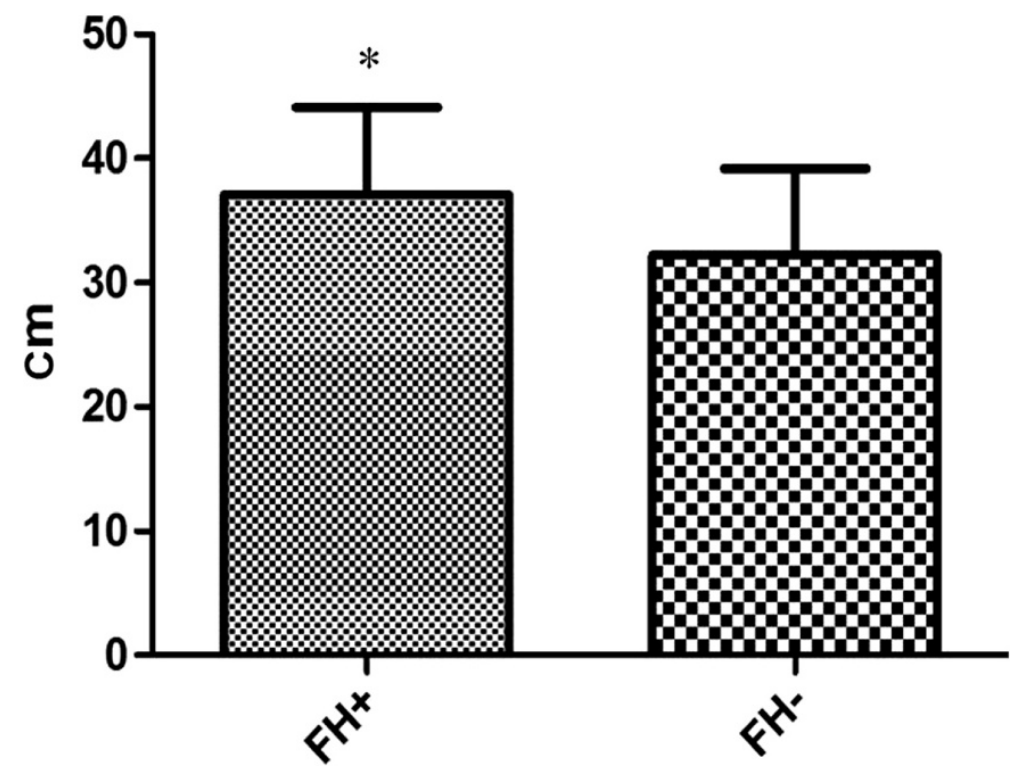

Figure 1 The figure is showing the squat jump performances of both groups.

of an exercise intervention on DNA methylation in skeletal muscle from first-degree relatives of patients with type 2 diabetes. The Authors identified epigenetic differences in muscle of $\mathrm{FH}+$ compared with $\mathrm{FH}$ - individuals. In more details, the differential DNA methylation of genes in biological pathways with key functions in muscle such as MAPK, insulin, and calcium signaling and of individual genes including PRKAB1 and MAPK1 (Nitert et al. 2012).
It is demonstrated that MAPK1 have an important physiological and metabolic roles in skeletal muscle (Wojtaszewski et al. 1999), moreover the protein encoded by PRKAB1 is a regulatory subunit of AMP-activated protein kinase, which is an enzyme that monitors cellular energy status and regulates metabolism in muscle (Hardie 2008). Nitert et al. demonstrate that exercise for 6 months is associated with decreased DNA methylation of MEF2A

\section{Squat Jump - Time}

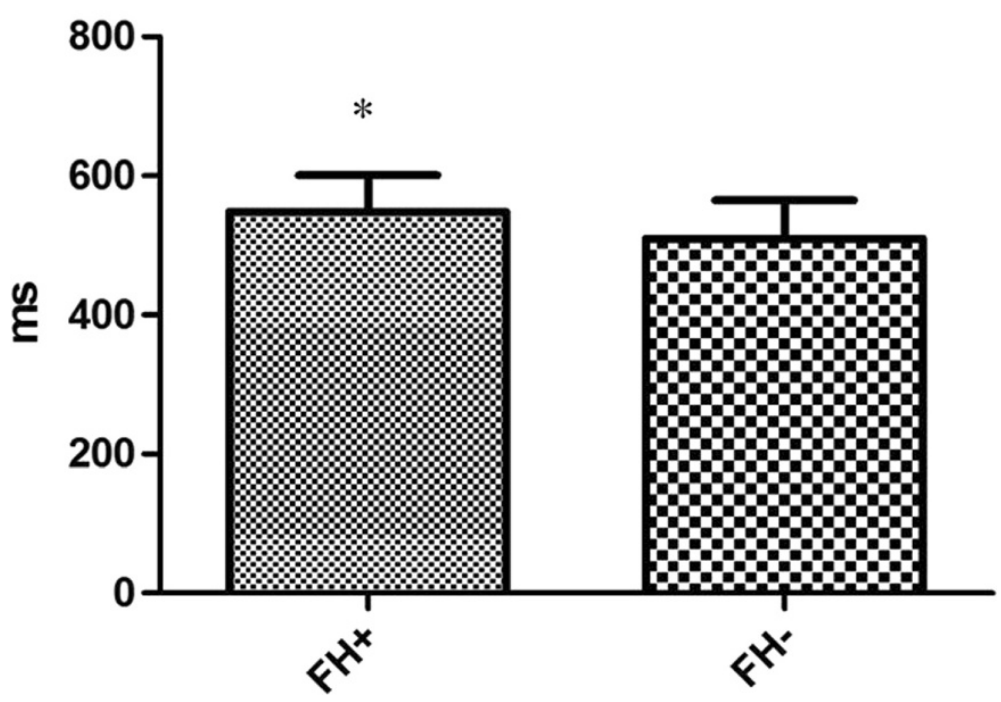

Figure 2 The figure represents the squat jump time of flight of both groups. 


\section{Wingate test}

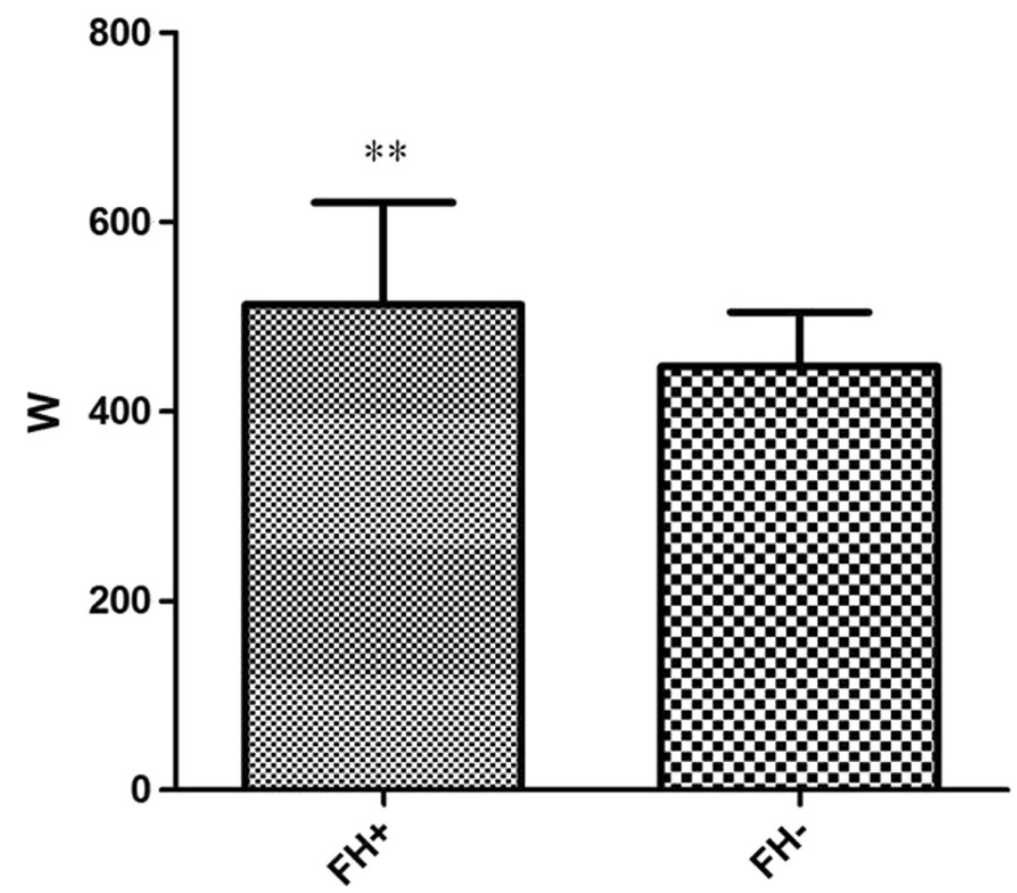

Figure 3 In this figure, the Wingate tests of both groups are present.

(Nitert et al. 2012). The MEF2A (Myocyte-specific Enhancer Factor 2A) is a transcription factor involved in the exercise-induced regulation of GLUT4 expression, and hence it may influence glucose uptake in muscle (McGee et al. 2006).

Moreover still in Nitert study a number of genes changed their expression after training period (all related to the muscle metabolism regulation) (Nitert et al. 2012). Those epigenetic differences seem to be related to a combination of FH to T2D with a long term practice of sport activities. This should be one possible explanation to a better anaerobic performance and higher FFM of our FH + participants.

\section{Conclusion}

The evidences that are coming out from this study are both interesting and unexpected. The élite athletes with FH toT2D showed better anaerobic performances and a higher body mass. This evidence seems to be supported by few observational studies carried out by our research

Table 3 Athletic performance with significant difference $(p<0,05)$

\begin{tabular}{lccc}
\hline Athletic performance & FH- $(\boldsymbol{n}=\mathbf{3 3})$ & $\mathbf{F H}+(\boldsymbol{n}=\mathbf{1 3})$ & $\boldsymbol{p}$ value \\
\hline Squat jump-height $(\mathrm{cm})$ & $33,23 \pm 6,95$ & $37,12 \pm 7$ & 0,0379 \\
Squat jump-flying time $(\mathrm{ms})$ & $509,82 \pm 55,01$ & $548,15 \pm 52,89$ & 0,0370 \\
Wingate test $(\mathrm{W})$ & $447,94 \pm 56,95$ & $512,77 \pm 107,93$ & 0,0116 \\
\hline
\end{tabular}

group and few clinical studies who deeper investigated the biological mechanisms responsible of phenotype mutation and epigenetic differentiation in people with $\mathrm{FH}$ toT2D. More studies with a larger number of participants are needed in order to consolidate this first study. At this stage we cannot generalise, but in a sample of athletes we tested, all who were with $\mathrm{FH}$ showed a significant better anaerobic performance; if confirmed, this evidence may represent an interesting knowledge for fitness coaches and professionals who are daily dealing with track and field athletes and their performances.

\section{Abbreviations}

BL: Blood lactate; BMR: Basal metabolic rate; FFM: Free-fat mass; FH: Family history; FH-: Subjects without family history to type 2 diabetes; FH+: Subjects with family history to type 2 diabetes; FM: Fat mass; HR: Heart rate; RNDI: Response Non-Dispersive Infrared; T2D: Type 2 diabetes; $\mathrm{VO}_{2}$ Max: Maximal oxygen uptake.

\section{Competing interest}

The authors declare that they have no competing interest.

\section{Authors' contributions}

All researchers have contributed equally to the research project. All authors read and approved the final manuscript.

\section{Acknowledgements}

We want to highlight the extra-effort of Staff of the MEDEOR Clinic for Metabolic disorders. Moreover, we want to thank all participants to the study for their patience.

\section{Funding}

The research was supported by the University of Palermo and the MEDEOR Research Institute, Palermo, Italy. 


\section{Author details}

${ }^{1}$ Sport and Exercise Sciences Research Unit, University of Palermo, Via Eleonora Duse 2, 90146 Palermo, Italy. ${ }^{2}$ MEDEOR Research Institute, Palermo, Italy. ${ }^{3}$ Department of Biomedical Science, University of Padua, Padova, Italy.

Received: 30 December 2013 Accepted: 29 April 2014

Published: 3 May 2014

\section{References}

Bianco A, Pomara F, Jemni M, Paoli A, Petrucci M, Bellafiore M, Palma A (2011) Influence of family history of NIDDM on basal metabolic rate in sedentary and active women. Panminerva Med 53(4):253-259

Bianco A, Pomara F, Thomas E, Paoli A, Battaglia G, Petrucci M, Proia P, Bellafiore M, Palma A (2013) Type 2 diabetes family histories, body composition and fast-ing glucose levels: a cross-section analysis in healthy se-dentary male and female. Iran J Public Health 42(7):9

Bianco A, Pomara F, Raccuglia M, Bellafiore M, Battaglia G, Filingeri D, Paoli A, Palma A (2014) The relationship between type 2 diabetes family history, body composition and blood basal glycemia in sedentary people. Acta Diabetol 51(1):79-84, doi:10.1007/s00592-013-0502-x

Bjornholt JV, Erikssen G, Liestol K, Jervell J, Thaulow E, Erikssen J (2000) Type 2 diabetes and maternal family history: an impact beyond slow glucose removal rate and fasting hyperglycemia in low-risk individuals? Results from 22.5 years of follow-up of healthy nondiabetic men. Diabetes Care 23(9):1255-1259

Bjornholt JV, Erikssen G, Liestol K, Jervell J, Erikssen J, Thaulow E (2001) Prediction of type 2 diabetes in healthy middle-aged men with special emphasis on glucose homeostasis. Results from 22.5 years' follow-up. Diabet Med 18(4):261-267

Christ-Roberts CY, Pratipanawatr T, Pratipanawatr W, Berria R, Belfort R, Mandarino $\sqcup$ (2003) Increased insulin receptor signaling and glycogen synthase activity contribute to the synergistic effect of exercise on insulin action. J Appl Physiol 95(6):2519-2529, doi:10.1152/japplphysiol.00605.2003

Crispim D, Canani LH, Gross JL, Tschiedel B, Souto KE, Roisenberg I (2006) Familial history of type 2 diabetes in patients from Southern Brazil and its influence on the clinical characteristics of this disease. Arq Bras Endocrinol Metabol 50(5):862-868

Ekelund U, Griffin SJ, Wareham NJ (2007) Physical activity and metabolic risk in individuals with a family history of type 2 diabetes. Diabetes Care 30(2):337-342, doi:10.2337/dc06-1883

Erasmus RT, Blanco Blanco E, Okesina AB, Mesa Arana J, Gqweta Z, Matsha T (2001) Importance of family history in type 2 black South African diabetic patients. Postgrad Med J 77(907):323-325

Geidl W, Pfeifer K (2011) Physical activity and exercise for rehabilitation of type 2 diabetes. Rehabilitation 50(4):255-265, doi:10.1055/s-0031-1280805

Golubic R, Wijndaele K, Sharp SJ, Simmons RK, Griffin SJ, Wareham NJ, Ekelund U, Brage S (2014) Physical activity, sedentary time and gain in overall and central body fat: seven year follow-up of the ProActive trial cohort. Int J Obes (Lond), doi:10.1038/ijo.2014.66. [Epub ahead of print]

Gordon BA, Bird SR, Macisaac RJ, Benson AC (2013) Glycemic response varies between resistance and aerobic exercise in inactive males with long-term type 2 diabetes. Appl Physiol Nutr Metab 38(8):900-904, doi:10.1139/apnm-2012-0494

Grill V, Persson G, Carlsson S, Norman A, Alvarsson M, Ostensson CG, Svanström L, Efendic S (1999) Family history of diabetes in middle-aged Swedish men is a gender unrelated factor which associates with insulinopenia in newly diagnosed diabetic subjects. Diabetologia 42(1):15-23, doi:10.1007/s001250051106

Hardie DG (2008) AMPK: a key regulator of energy balance in the single cell and the whole organism. Int J Obes (Lond) 32(Suppl 4):S7-S12, doi:10.1038/ijo.2008.116

Hawley JA, Gibala MJ (2012) What's new since Hippocrates? Preventing type 2 diabetes by physical exercise and diet. Diabetologia 55(3):535-539, doi:10.1007/s00125-012-2460-1

Kim Y, Lee S (2009) Physical activity and abdominal obesity in youth. Appl Physiol Nutr Metab 34(4):571-581, doi:10.1139/H09-066

Kourtoglou Gl (2011) Insulin therapy and exercise. Diabetes Res Clin Pract 93 (Suppl 1):S73-S77, doi:10.1016/S0168-8227(11)70017-1

Kwon HR, Han KA, Ku YH, Ahn HJ, Koo BK, Kim HC, Min KW (2010) The effects of resistance training on muscle and body fat mass and muscle strength in type 2 diabetic women. Korean Diabetes J 34(2):101-110, doi:10.4093/kdj.2010.34.2.101

Mahajan A, Sharma S, Dhar MK, Bamezai RN (2013) Risk factors of type 2 diabetes in population of Jammu and Kashmir, India. J Biomed Res 27(5):372-379, doi:10.7555/JBR.27.20130043
Mann S, Beedie C, Balducci S, Zanuso S, Allgrove J, Bertiato F, Jimenez A (2013) Changes in insulin sensitivity in response to different modalities of exercise: a review of the evidence. Diabetes Metab Res Rev 30(4):257-68, doi:10.1002/dmrr.2488

McGee SL, Sparling D, Olson AL, Hargreaves M (2006) Exercise increases MEF2- and GEF DNA-binding activity in human skeletal muscle. FASEB J 20(2):348-349, doi:10.1096/fj.05-4671fje

Nitert MD, Dayeh T, Volkov P, Elgzyri T, Hall E, Nilsson E, Yang BT, Lang S, Parikh $H$, Wessman $Y$, Weishaupt $H$, Attema J, Abels M, Wierup N, Almgren $P$, Jansson PA, Ronn T, Hansson O, Eriksson KF, Groop L, Ling C (2012) Impact of an exercise intervention on DNA methylation in skeletal muscle from first-degree relatives of patients with type 2 diabetes. Diabetes 61:3322-3332, doi:10.2337/db11-165310.2337/db11-1653. Epub 2012 Oct 1

Nyholm B, Nielsen MF, Kristensen K, Nielsen S, Ostergard T, Pedersen SB, Christiansen T, Richelsen B, Jensen MD, Schmitz $O$ (2004) Evidence of increased visceral obesity and reduced physical fitness in healthy insulin-resistant first-degree relatives of type 2 diabetic patients. Eur J Endocrinol 150(2):207-214

O'Hagan C, De Vito G, Boreham CA (2013) Exercise prescription in the treatment of type 2 diabetes mellitus: current practices, existing guidelines and future directions. Sports Med 43(1):39-49, doi:10.1007/s40279-012-0004-y

Plagemann A, Harder T, Franke K, Kohlhoff R (2002) Long-term impact of neonatal breast-feeding on body weight and glucose tolerance in children of diabetic mothers. Diabetes Care 25(1):16-22

Pomara F, Russo G, Gravante G (2006) Influence of family history to type 2 diabetes on the body composition and homeostasis model assessment: a comparison between young active and sedentary men. Minerva Med 97(5):379-383

Rodekamp E, Harder T, Kohlhoff R, Franke K, Dudenhausen JW, Plagemann A (2005) Long-term impact of breast-feeding on body weight and glucose tolerance in children of diabetic mothers: role of the late neonatal period and early infancy. Diabetes Care 28(6):1457-1462

Rosenbaum M, Fennoy I, Accacha S, Altshuler L, Carey DE, Holleran S, Rapaport R, Shelov SP, Speiser PW, Ten S, Bhangoo A, Boucher-Berry C, Espinal Y, Gupta $R$, Hassoun AA, lazetti $L$, Jean-Jacques $F$, Jean AM, Klein $M L$, Levine $R$, Lowell B, Michel L, Rosenfeld W (2013) Racial/ethnic differences in clinical and biochemical type 2 diabetes mellitus risk factors in children. Obesity 21(10):2081-2090, doi:10.1002/oby.20483

Wojtaszewski JF, Lynge J, Jakobsen AB, Goodyear LJ, Richter EA (1999) Differential regulation of MAP kinase by contraction and insulin in skeletal muscle: metabolic implications. Am J Physiol 277(4 Pt 1):E724-E732

Wood RJ, O'Neill EC (2012) Resistance training in type II diabetes mellitus: impact on areas of metabolic dysfunction in skeletal muscle and potential impact on bone. J Nutr Metab 2012:268197, doi:10.1155/2012/268197

doi:10.1186/2193-1801-3-224

Cite this article as: Bianco et al:: The surprising influence of family history to type 2 diabetes on anaerobic performance of young male élite athletes. SpringerPlus 2014 3:224.

\section{Submit your manuscript to a SpringerOpen ${ }^{\odot}$ journal and benefit from:}

- Convenient online submission

$\checkmark$ Rigorous peer review

- Immediate publication on acceptance

- Open access: articles freely available online

- High visibility within the field

- Retaining the copyright to your article

Submit your next manuscript at $>$ springeropen.com 